\title{
The Aachen Falls Prevention Scale: Multi-Study Evaluation and Comparison
}

Peter Rasche ${ }^{1}$, Dr rer medic; Verena Nitsch ${ }^{1}$, Dr-Ing; Lars Rentemeister ${ }^{2}$; Mark Coburn ${ }^{3}$, Dr med; Benjamin Buecking ${ }^{4}$, Dr med; Christopher Bliemel ${ }^{4}$, Dr med; Leo Cornelius Bollheimer ${ }^{5}$, Dr med; Hans-Christoph Pape ${ }^{6}$, Dr med; Matthias $\mathrm{Knobe}^{2}$, Dr med, MME, MHBA

\footnotetext{
${ }^{1}$ Institute of Industrial Engineering and Ergonomics, Department of Mechanical Engineering, RWTH Aachen University, Aachen, Germany

${ }^{2}$ Department of Orthopaedic Trauma, University of Aachen Medical Center, RWTH Aachen University, Aachen, Germany

${ }^{3}$ Klinik für Anästhesiologie, University of Aachen Medical Center, RWTH Aachen University, Aachen, Germany

${ }^{4}$ Center for Orthopaedics and Trauma Surgery, University Hospital of Giessen and Marburg, Marburg, Germany

${ }^{5}$ Department of Geriatrics, University of Aachen Medical Center, RWTH Aachen University, Aachen, Germany

${ }^{6}$ Department of Orthopaedic Trauma, University of Zurich Medical Center, University of Zurich, Zurich, Switzerland
}

\section{Corresponding Author:}

Peter Rasche, Dr rer medic

Institute of Industrial Engineering and Ergonomics

Department of Mechanical Engineering

RWTH Aachen University

Bergdriesch 27

Aachen, 52062

Germany

Phone: $49+492418099477$

Email: p.rasche@iaw.rwth-aachen.de

\section{Abstract}

Background: Fall risk assessment is a time-consuming and resource-intensive activity. Patient-driven self-assessment as a preventive measure might be a solution to reduce the number of patients undergoing a full clinical fall risk assessment.

Objective: The aim of this study was (1) to analyze test accuracy of the Aachen Falls Prevention Scale (AFPS) and (2) to compare these results with established fall risk assessment measures identified by a review of systematic reviews.

Methods: Sensitivity, specificity, and receiver operating curves (ROC) of the AFPS were calculated based on data retrieved from 2 independent studies using the AFPS. Comparison with established fall risk assessment measures was made by conducting a review of systematic reviews and corresponding meta-analysis. Electronic databases PubMed, Web of Science, and EMBASE were searched for systematic reviews and meta-analyses that reviewed fall risk assessment measures between the years 2000 and 2018. The review of systematic reviews was conducted in accordance with the Preferred Reporting Items for Systematic Reviews and Meta-Analysis statement. The Revised Assessment of Multiple SysTemAtic Reviews (R-AMSTAR) was used to assess the methodological quality of reviews. Sensitivity, specificity, and ROC were extracted from each review and compared with the calculated values of the AFPS.

Results: Sensitivity, specificity, and ROC of the AFPS were evaluated based on 2 studies including a total of 259 older adults. Regarding the primary outcome of the AFPS subjective risk of falling, pooled sensitivity is 57.0\% (95\% CI 0.467-0.669) and specificity is $76.7 \%$ (95\% CI 0.694-0.831). If 1 out of the 3 subscales of the AFPS is used to predict a fall risk, pooled sensitivity could be increased up to $90.0 \%$ (95\% CI 0.824-0.951), whereas mean specificity thereby decreases to 50.0\% (95\% CI 0.42-0.58). A systematic review for fall risk assessment measures produced 1478 articles during the study period, with 771 coming from PubMed, 530 from Web of Science, and 177 from EMBASE. After eliminating doublets and assessing full text, 8 reviews met the inclusion criteria. All were of sufficient methodological quality (R-AMSTAR score $\geq 22$ ). A total number of 9 functional or multifactorial fall risk assessment measures were extracted from identified reviews, including Timed Up and Go test, Berg Balance Scale, Performance-Oriented Mobility Assessment, St Thomas's Risk Assessment Tool in Falling Elderly, and Hendrich II Fall Risk Model. Comparison of these measures with pooled sensitivity and specificity of the AFPS revealed a sufficient quality of the AFPS in terms of a patient-driven self-assessment tool. 
Conclusions: It could be shown that the AFPS reaches a test accuracy comparable with that of the established methods in this initial investigation. However, it offers the advantage that the users can perform the self-assessment independently at home without involving trained health care professionals.

(JMIR Aging 2019;2(1):e12114) doi: 10.2196/12114

\section{KEYWORDS}

meta-analysis; elderly; self-assessment; hip injuries; leg injuries; sensitivity; specificity

\section{Introduction}

\section{Background}

Fall incidents are an increasing problem in aging societies [1]. Every third adult older than 65 years falls at least once a year [2]. Increased morbidity and mortality are typical consequences of this fall incidence or related injuries [3-5]. In addition, each individual's risk of falling is generally difficult to detect and is likely to be underestimated [2]. Thus, routinely assessing an individual's fall risk is recommended within the United States, United Kingdom, and Germany [6-8]. This assessment is mainly carried out by the family doctor and is based on the question about fall incidents or the subjective fear of falling. In the event that a potential risk is identified, further functional or multifactorial case risk assessment measures are applied. The National Institute for Health and Care Excellence (NICE, United Kingdom) recommends a multifactorial assessment for suspected cases of outpatients, which aims at different risk factors and does not only evaluate the pure mobility of the patients [7]. The United States Preventive Service Task Force (US PSTF, United States), on the other hand, recommends keeping the assessment as simple as possible and asking patients about their fall history as well as carrying out a functional assessment such as the Timed Up and Go Test [8]. The German College of General Practitioners and Family Physicians recommends a similar assessment as the US PSTF based on questioning patients' fall history and assessing their fall risk based on a functional test like the Timed Up and Go test [6]. A comparison of these guidelines shows that there is still no common best practice for assessing individual fall risks in different industrial nations. What all 3 approaches have in common, however, is that the initiative to carry out an assessment always emanates from the treating family doctor and, in addition, because of a multifactorial or functional assessment, is very resource-intensive and time-consuming [9-13]. Many of them are also problematic in terms of their interrater reliability [14-19]. Preventive measures are, thus, difficult and demand sufficient integration and implementation into aftercare and outpatient management $[9,10,14,20,21]$. Especially if patients' fall risk should be monitored over a long term, clinical assessment measures are oversized and unsuitable, particularly in terms of a low-threshold service. This leads to the inclusion of a high proportion of low-risk people and waste of resources in terms of clinical setting.

Patient-driven self-assessment as a preventive measure might be a solution [14,22,23]. A promising approach for patient-guided self-assessment of personal fall risk is the Aachen Falls Prevention Scale (AFPS) [11]. On the basis of a 3-step multifactorial and functional assessment, users can evaluate their personal risk of falling. The first step includes 10 yes/no questions (subscale 1) covering typical risk factors such as cognitive or visual impairment, continence problems, falls history, footwear that is unsuitable, health problems that may increase their risk of falling (osteoporosis, Parkinson, arthrosis, or rheumatic disease), or medication. The second step involves a 10 -second free-standing test (subscale 2), enabling the users to identify certain balance problems by themselves. The third step is a self-evaluation on a 10-point Likert-type scale (third subscale and primary outcome of the AFPS). Users should rate their subjective risk of falling in regard to the results of the risk factor assessment and the balance test [11]. Thus, the AFPS incorporates a multifactorial fall risk assessment as recommended by NICE or the US PSTF [7,8]. The scale is designed to be used by older adults themselves. This is a benefit compared with most multifactorial fall risk assessments, as is mentioned before. In addition, older adults could perform this self-assessment on their own using a paper version of the AFPS or the corresponding Aachen Falls Prevention App (AFPA) [24]. Thus, older adults get empowered to assess their risk of falling on their own and to consult a physician in advance. In addition, it is also possible to reach groups of people who do not regularly take part in preventive examinations or checkups with their family doctor. For example, the corresponding self-assessment can be sent by the health insurance company. The advantage for the physicians treating the patients is that the self-assessment of the patient provides them with direct information about the existence of risk indicators. In addition, regular use of the AFPS will give an overview of these risk indicators, of balance problems, or of the self-perceived risk of falls changing over time. However, it is still open to what extent the AFPS is covered by clinical multifactorial assessments, which are carried out in a clinical environment with a high time and personnel expense.

\section{Aim of This Study}

The purpose of this study was (1) to analyze the test accuracy of the AFPS and (2) to compare these results with established fall risk assessment measures identified by a review of systematic reviews.

\section{Methods}

The objective of this study was to determine the sensitivity, specificity, and area under the curve (AUC) via receiver operating curves (ROCs) of the AFPS and to compare them with established measures. Accordingly, the methodological approach of this work is divided into 2 steps. In the first step, the corresponding characteristic values (sensitivity, specificity, and AUC) are calculated. In the second step, a systematic literature search was carried out with the aim of identifying 
relevant reviews of established case risk assessment measures so that the calculated AFPS characteristics can be compared with these.

\section{Test Accuracy Analysis of the Aachen Falls Prevention Scale}

The first objective of this study was to determine the test accuracy of the AFPS. The AFPS has 3 binary outcomes (positive/negative) associated with the 3 steps performed during self-assessment. Sensitivity and specificity were calculated regarding the primary outcome of the AFPS subjective risk of falling. Subsequently, sensitivity and specificity were calculated in the case that 1 out of the 3 outcomes of the AFPS identified a positive overall result. The same procedure was applied for the calculation of the ROC and thus the AUC values.

\section{Sensitivity and Specificity}

Sensitivity and specificity were calculated as described by Lalkhen and McCluskey, Lusardi et al, and Oliver et al [25-27]. Calculations were performed using Statistical Package of Social Science (SPSS) version 22 (IBM Corp). Pooled sensitivity and specificity were calculated using Meta-DiSc1.4 (Clinical Biostatistics team of the Ramón y Cajal Hospital in Madrid) [28].

\section{Receiver Operating Curves and Area Under the Curve}

Second, the reliability of the AFPS was analyzed by plotting ROCs. These curves plot the sensitivity against (1-specificity) for all possible parameter values. The ROC and the line of no discrimination (diagonal) differ from each other if the parameters analyzed are not randomly related. The AUC could be used to quantify this result. In case of a random relationship, the AUC value is 0.5 . In the range between 0.5 and 0.7 for the AUC value, a test is considered less accurate, whereas in the range from greater than 0.7 to 0.9 , it is considered moderately accurate. A perfect test would have an AUC value of $1[29,30]$. ROCs and AUCs were calculated using Bland-Altman analyses performed in SPSS separately for both studies.

\section{Data Collection}

Data from 2 studies by Knobe et al and Rasche et al, in which the AFPS was included, were used for test accuracy analysis $[31,32]$. In both studies, identification of fallers was performed according to the definition by Panzer et al [12,31,32]. Utilizing the fall risk screening criteria, participants reporting greater than or equal to 2 noninjury falls in the past year or greater than or equal to 1 injury fall were categorized as fallers; participants reporting no falls were categorized as nonfallers [31]. The test accuracy of the AFPS was calculated compared with this binary classification.

\section{Comparison of the Aachen Falls Prevention Scale With Established Assessment Measures}

The second aim of this study was to compare the sensitivity, specificity, and AUC values of the AFPS with established fall risk assessment measures. Hence, a review of systematic reviews was conducted to retrieve reliable sensitivity, specificity, and AUC values from literature. This review of systematic reviews was carried out in accordance with the Preferred Reporting
Items for Systematic Reviews and Meta-Analysis (PRISMA) statement [33].

\section{Inclusion and Exclusion Criteria}

Only reviews that fulfilled the following criteria were included: (1) published between the years 2000 and 2018, (2) stating specific values for sensitivity and specificity or AUC, (3) including fall risk assessment measures designed for outpatient application, (4) no specific investigation of a diseased subgroup of older adults, such as, for example, dementia patients.

\section{Search Methods}

Due to the aim of this study, only the electronic databases PubMed, EMBASE, and Web of Science were searched in July and November 2018. The search term was, because of the purpose of this study, defined as fall risk assessment. Reference lists from the identified publications were reviewed to identify additional research articles of interest.

\section{Selection Process}

Titles of records resulting from the literature search were independently screened by the first author and discussed with the coauthors. When further clarification was needed, the abstracts were consulted, and in a third step, the full text was retrieved. Disagreements were resolved by the senior author.

\section{Data Extraction and Management}

The authors extracted the following data and resolved any disagreements in consultation with the senior author: (1) authorship and publication-related information; (2) name of fall risk assessment measures reviewed; (3) overall sample size; (4) sensitivity and specificity values of the fall risk assessment measures; (5) and if available, AUC value for the fall risk assessment measures. Data were only extracted for the case risk assessment measures, which were examined in at least 2 of the 8 identified reviews. This procedure should ensure that the comparison was not based solely on the data from a single review. Furthermore, this procedure should ensure that scientifically relevant and correspondingly frequently discussed fall risk assessment measures were included in the comparison.

\section{Methodological Quality Assessment}

The Revised Assessment of Multiple SysTemAtic Reviews (R-AMSTAR) was used to quantitatively evaluate the methodological quality of identified systematic reviews regarding the inclusion in this study [34]. Reviews are evaluated by the presence of the following 11 domains: (1) an a priori design, (2) duplicate study selection and data extraction, (3) a comprehensive literature search, (4) the use of status of publication as an inclusion criteria, (5) a list of included/excluded studies, (6) characteristics of included studies, (7) documented assessment of the scientific quality of included studies, (8) appropriate use of the scientific quality in forming conclusions, (9) the appropriate use of methods to combine findings of studies, (10) assessment of the likelihood of publication bias, and (11) documentation of conflicts of interest [35]. Each domain is rated on a 4-point scale, whereas R-AMSTAR total scores range from 11 to 44 points. For inclusion of the evaluated review, a total score of 22 points was required [34]. The authors in charge of extracting data from the 
selected reviews also preliminarily and independently assessed the methodological quality of the contributions. The supervising author resolved any discrepancies.

\section{Data Synthesis}

Identified reviews were analyzed, and relevant data were extracted and recorded according to prior descriptions. Comparison of test accuracy data between established fall risk assessment measures and AFPS was performed descriptively.

\section{Results}

\section{Test accuracy of the Aachen Fall Prevention Scale}

\section{Sensitivity and Specificity}

Calculations were made based on 2 studies. The first sample retrieved from Knobe et al included 163 older adults (mean age 80.4 years, SD 6.4) [31]. The second one retrieved from Rasche et al contains 96 older adults with a mean age of 63.8 years (SD 7.02) [32]. Table 1 shows relevant data retrieved from the 2 studies.

Data from the study by Knobe et al [31] revealed a sensitivity of $56 \%$ (specificity of $64 \%$ ) for the primary outcome parameter (self-assessment on 10-point Likert-scale) of the AFPS. If 1 out of the 3 outcome parameters of the AFPS is used to determine a positive result, then sensitivity could be increased up to $93 \%$, whereas specificity thereby decreases to $11 \%$. Calculations based on the data retrieved from the study by Rasche et al [32] showed a sensitivity of $66.7 \%$ (specificity $88.1 \%$ ) for the primary outcome parameter of the AFPS. If just 1 out of the 3 parameters is used to determine a positive result, the sensitivity was again $66.7 \%$, with a specificity of $84.5 \%$.

Regarding the primary outcome of the AFPS (third subscale; 10-point Likert-type scale), pooled sensitivity is $57.0 \%$ (95\% CI 0.467-0.669) and specificity is 76.7\% (95\% CI 0.694-0.831; see Figure 1).

If 1 out of the 3 subscales of the AFPS is used to determine a fall risk, pooled sensitivity is increases up to $90 \%$ (95\% CI $0.824-0.951)$ and specificity decreases to $50 \%(95 \% \mathrm{CI}$ 0.42-0.58; see Figure 2).

\section{Receiver Operating Curves and Area Under the Curve}

Following ROCs are described regarding the different outcome parameters of the AFPS. Calculations were made with SPSS. Figure 3 shows the test criteria of the primary outcome parameter of the AFPS using ROCs to discriminate between fallers and nonfallers. For the sample retrieved from the study by Knobe et al [31], the AUC for the primary outcome parameter of the AFPS was 0.692 (SE 0.043) and a 95\% CI of 0.606-0.777. The AUC for the data retrieved from the study by Rasche et al [32] was 0.873 (SE 0.04) with a 95\% CI of 0.796-0.980.

Figure 4 shows the test criteria of ROCs to discriminate between fallers and nonfallers for the AFPS if 1 out of the 3 subscales is used to determine a fall risk.

The AUC for 1 out of the 3 subscales was calculated to 0.629 (SE 0.044) and a 95\% CI ranging from 0.543 to 0.716 for the data extracted from the study by Knobe et al [31]. The sample retrieved from the study by Rasche et al [32] revealed an AUC of 0.756 (SE 0.084) and a 95\% CI ranging from 0.592 to 0.920.

Table 1. Data extracted for calculating sensitivity and specificity of the Aachen Falls Prevention Scale.

\begin{tabular}{|c|c|c|c|c|}
\hline \multirow[t]{2}{*}{ Variable } & Faller (score) & & Nonfaller (score) & \\
\hline & Knobe et al (2018) [31] & Rasche et al (2018) [32] & Knobe et al (2018) [31] & Rasche et al (2018) [32] \\
\hline
\end{tabular}

Aachen Falls Prevention Scale (primary outcome)

$\begin{array}{lllll}\text { Subjective risk of falling } \geq 5^{\mathrm{a}} & 49^{\mathrm{b}} & 8^{\mathrm{b}} & 27^{\mathrm{c}} & 10^{\mathrm{c}} \\ \text { Subjective risk of falling }<5 & 39^{\mathrm{d}} & 4^{\mathrm{d}} & 48^{\mathrm{e}} & 74^{\mathrm{e}} \\ \text { Total } & 88 & 12 & 75 & 84\end{array}$

Aachen Falls Prevention Scale (1 out of the 3 criteria)

\begin{tabular}{|c|c|c|c|c|}
\hline $\begin{array}{l}\text { Balance test or Self-test } \geq 5 \text { or subjective } \\
\text { risk of falling } \geq 5^{f}\end{array}$ & $82^{b}$ & $8^{\mathrm{b}}$ & $67^{\mathrm{c}}$ & $13^{\mathrm{c}}$ \\
\hline $\begin{array}{l}\text { Balance test }+ \text { or Self-test }<5 \text { or subjective } \\
\text { risk of falling }<5\end{array}$ & $6^{\mathrm{d}}$ & $4^{\mathrm{d}}$ & $8^{\mathrm{e}}$ & $71^{\mathrm{e}}$ \\
\hline Total & 88 & 12 & 75 & 84 \\
\hline
\end{tabular}

\footnotetext{
${ }^{\mathrm{a}}$ Main outcome of the AFPS was positive ( $>5$ points in the subjective fall risk assessment).

${ }^{\mathrm{b}}$ Correct positive.

${ }^{\mathrm{c}}$ False positive.

${ }^{\mathrm{d}}$ False negative.

${ }^{\mathrm{e}}$ Correct negative.

${ }^{\mathrm{f}}$ At least 1 of the 3 criteria of the AFPS was positive and compared with the number of fall incidents ( $\mathrm{n} \geq 2$, or $\mathrm{n} \geq 1+1$ injury) within the last year.
} 
Figure 1. Pooled sensitivity and specificity regarding the primary outcome parameter of the Aachen Falls Prevention Scale. circles: study samples sensitivity/specificity; blue bars: CI of sensitivity/specificity; diamond: pooled sensitivity/specificity; red lines: CI of pooled sensitivity/specificity.

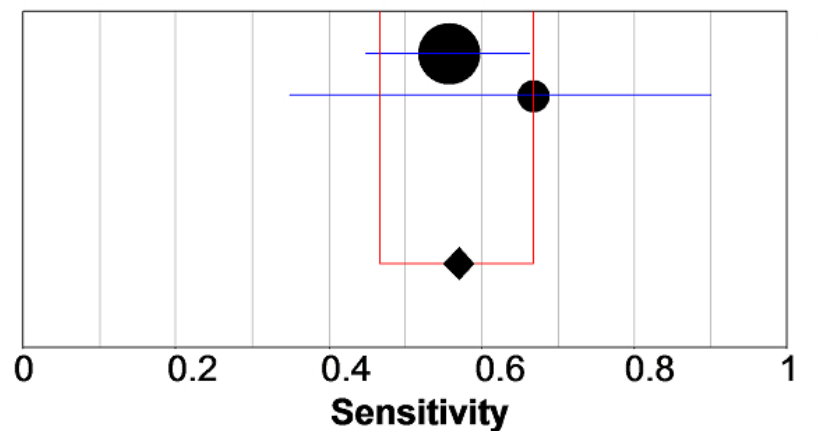

Knobe et al [31]

Rasche et al [32]

Pooled Sensitivity $=0.57(0.47$ to 0.67$)$

Chi-square $=0.53 ; \mathrm{df}=1(P=0.4660)$

Inconsistency (I-square) $=0.0 \%$

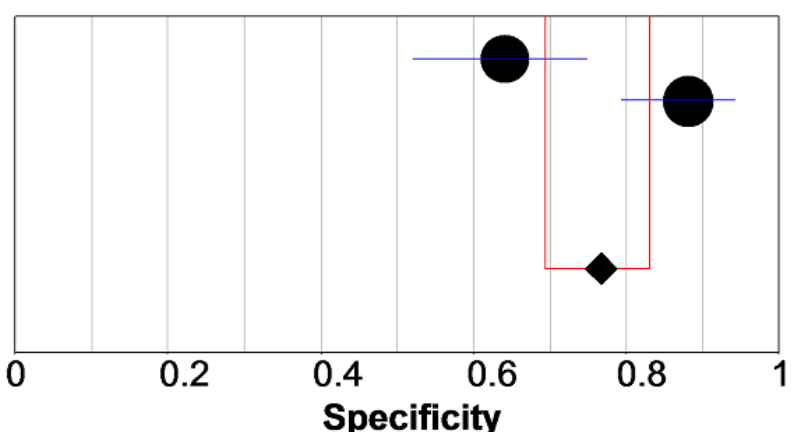

Sensitivity $(95 \% \mathrm{Cl})$

$0.56 \quad(0.45-0.66)$

$0.67 \quad(0.35-0.90)$

\section{Specificity $(95 \% \mathrm{Cl})$}

$\begin{array}{lll}\text { Knobe et al [31] } & 0.64 & (0.52-0.75) \\ \text { Rasche et al [32] } & 0.88 & (0.79-0.94)\end{array}$

Rasche et al [32]

$0.88 \quad(0.79-0.94)$

Pooled Specificity $=0.77$ (0.69 to 0.83 )

Chi-square $=13.19 ; \mathrm{df}=1(P=0.0003)$

Inconsistency (I-square) $=92.4 \%$

Figure 2. Pooled sensitivity and specificity regarding 1 out of the 3 steps of the Aachen Falls Prevention Scale. circles: study samples sensitivity/specificity; blue bars: CI of sensitivity/specificity; diamond: pooled sensitivity/specificity; red lines: CI of pooled sensitivity/specificity.

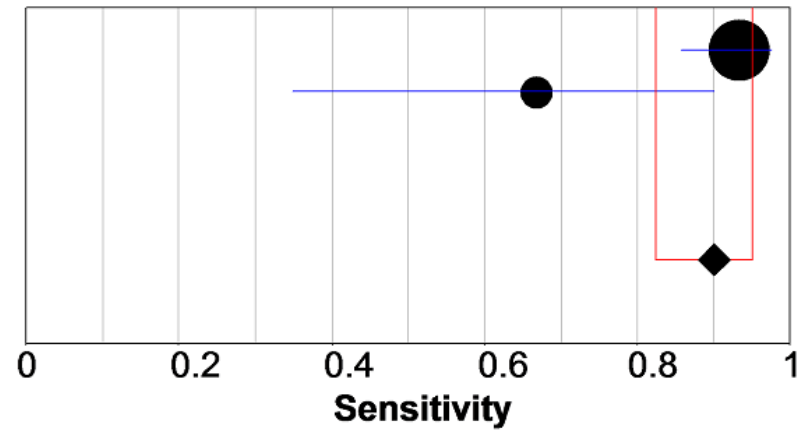

Knobe et al [31]

Rasche et al [32]

Sensitivity $(95 \% \mathrm{Cl})$

$0.93 \quad(0.86-0.97)$

$0.67 \quad(0.35-0.90)$

Pooled Sensitivity $=0.90(0.82$ to 0.95$)$

Chi-square $=5.93 ; \mathrm{df}=1(P=0.0149)$

Inconsistency (I-square) $=83.1 \%$

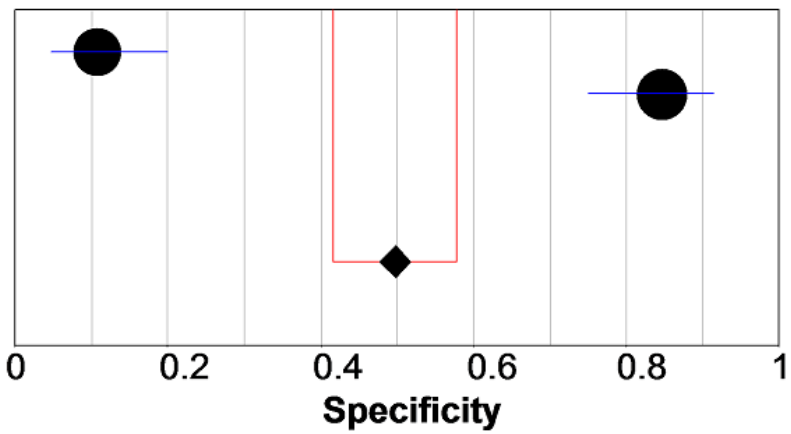

Knobe et al [31]

Rasche et al [32]

$05-0.20)$

$0.85 \quad(0.75-0.91)$

Pooled Specificity $=0.50(0.42$ to 0.58$)$

Chi-square $=97.10 ; \mathrm{df}=1(P=0.0000)$

Inconsistency (I-square) $=99.0 \%$ 
Figure 3. Receiver operating curves regarding primary outcome parameter (third subscale) of the Aachen Falls Prevention Scale to discriminate between fallers and nonfallers. Left side: Knobe et al [31] and right side: Rasche et al [32]; blue lines: receiver operating curves.

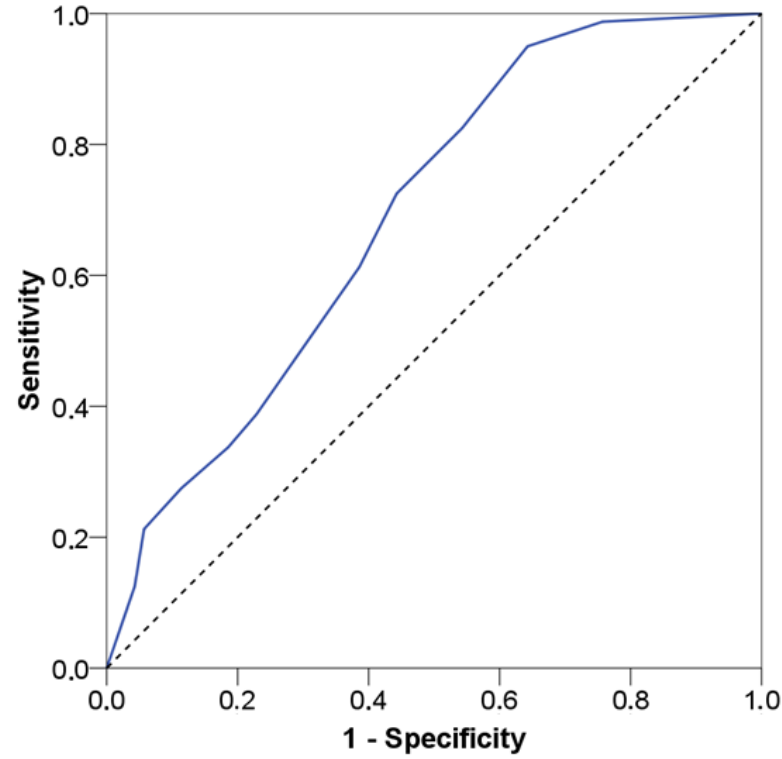

Diagonal segments are produced by ties

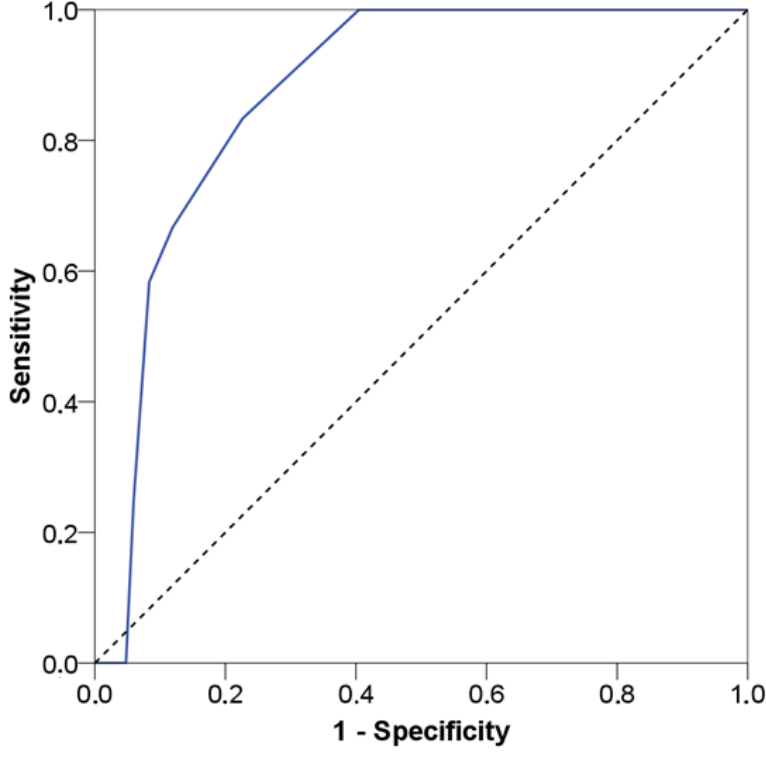

Diagonal segments are produced by ties

Figure 4. Receiver operating curves if 1 out of the 3 subscales of the Aachen Falls Prevention Scale is used to determine a fall risk. Left side: Knobe et al [31] and right side: Rasche et al [32]; blue lines: receiver operating curves.

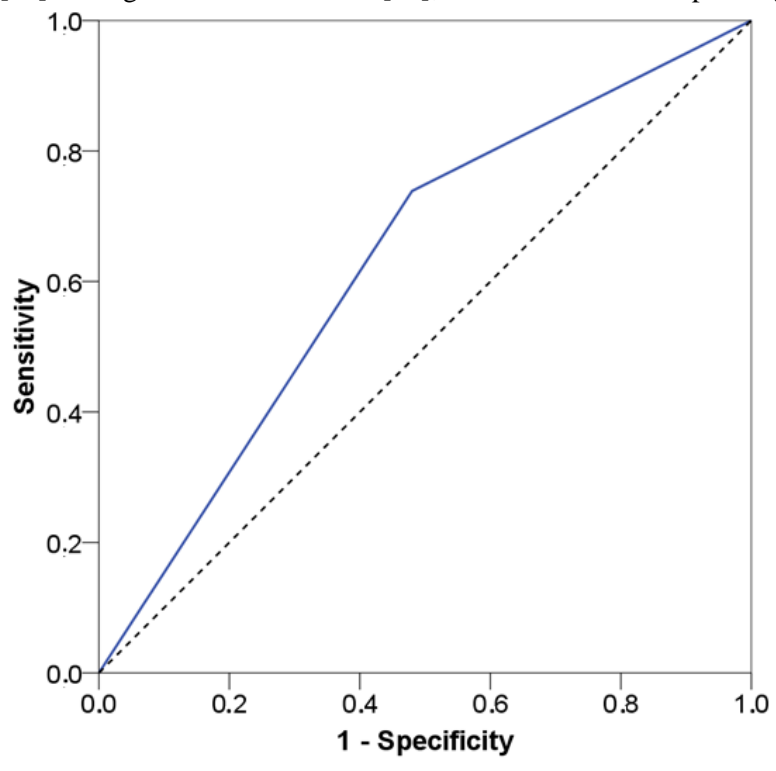

Diagonal segments are produced by ties

\section{Comparison of the AFPS with Established Assessment Measures}

Figure 5 shows the article identification and selection process. In total, 948 articles were identified through keyword and reference search within PubMed and EMBASE databases. Of them, 937 articles were excluded after title and abstract screening. The remaining 11 articles were read full-text. Of them, 4 articles were excluded as these were unavailable to the authors. A further article was excluded as it did not fit the scope of this review. The remaining 6 articles were included in the review [25,26,36-41]. For all 6 reviews, the R-AMSTAR score was higher than 22 points (mean 40 points, range: $36-42$ points).

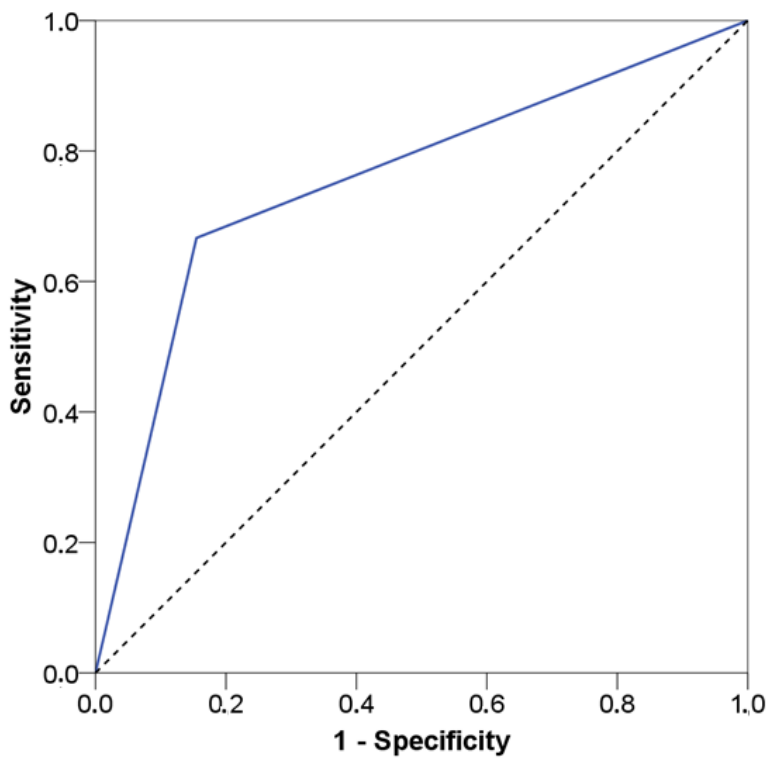

Diagonal segments are produced by ties

\section{Extracted Data}

Table 2 gives an overview of the identified articles using the previously defined parameters: publication-related information, name of fall risk assessment measure, sample size, sensitivity, specificity, and AUC.

\section{Data Aggregation and Comparison of Fall Risk Assessment Measures}

Table 3 shows the extracted sensitivity and specificity values for the different fall risk assessment measures by means of mean value and range. Further corresponding values of the AFPS were included for comparison. 
Figure 5. Results of the review of systematic reviews according to Preferred Reporting Items for Systematic Reviews and Meta-Analysis.
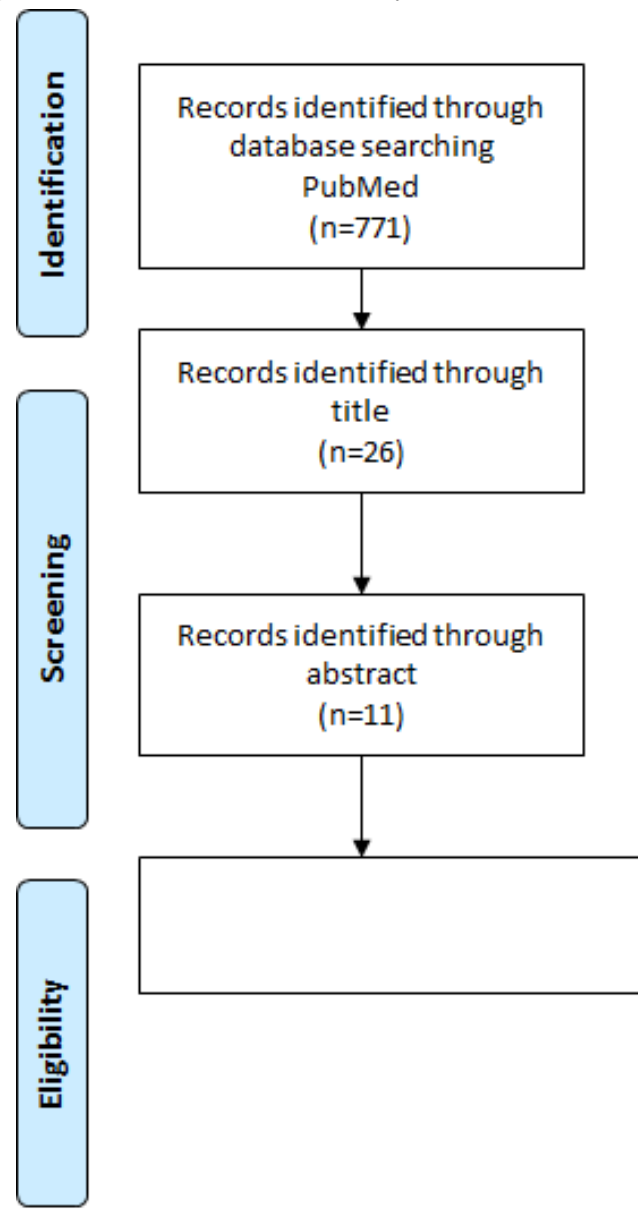
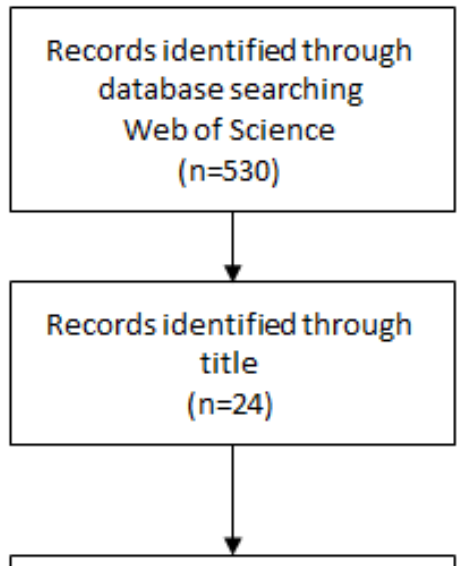

Records identified through abstract $(n=9)$

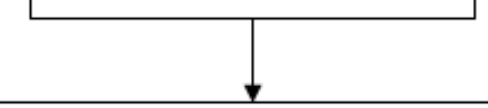

Records after duplicates removed $(n=15)$

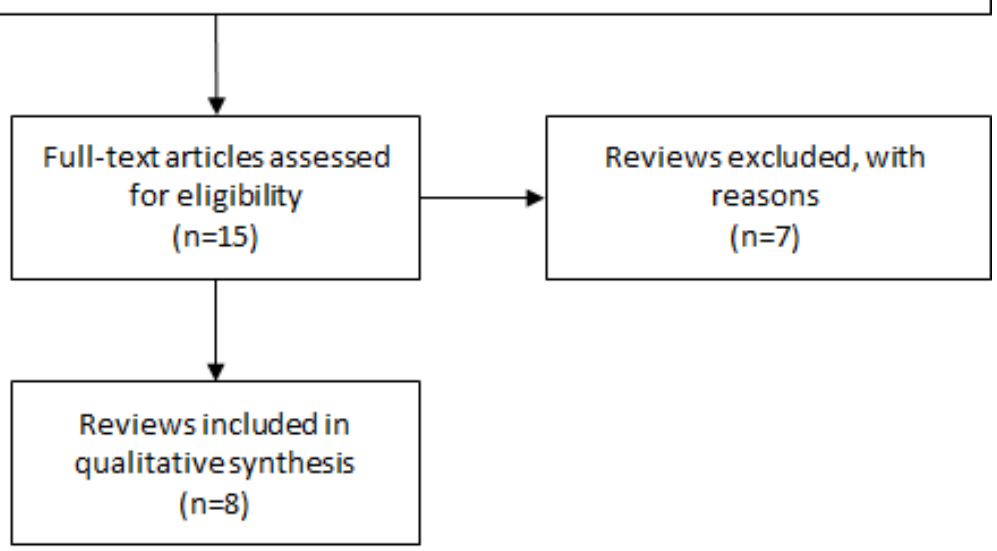


Table 2. Overview of identified reviews and extracted data for the meta-analysis.

\begin{tabular}{|c|c|c|c|c|}
\hline Study and fall risk assessment measure & Sample size, $\mathrm{N}$ & Sensitivity, \% & Specificity, \% & Area under the curve (SE) \\
\hline \multicolumn{5}{|l|}{ Perell (2001) [39] } \\
\hline Berg Balance Scale & $-^{\mathrm{a}}$ & 77.0 & 86.0 & - \\
\hline Dynamic Gait Index & 133 & 85.0 & 38.0 & - \\
\hline Elderly Fall Screening Test & 361 & 93.0 & 78.0 & - \\
\hline Timed Up and Go & 30 & 87.0 & 87.0 & - \\
\hline Performance-Oriented Mobility Assessment (Tinetti) & 79 & 80.0 & 74.0 & - \\
\hline \multicolumn{5}{|l|}{ Oliver et al (2004) [26] } \\
\hline Downton Fall Risk Index & 135 & 90.6 & 26.8 & - \\
\hline Innes Score & 2968 & 89.3 & 73.5 & - \\
\hline Morse Score & $2689 ; 483$ & $73.2 ; 95.7$ & $75.1 ; 54.0$ & - \\
\hline Schmid Score & 2405 & 92.5 & 78.2 & - \\
\hline STRATIFY ${ }^{b}$ & $395 ; 446 ; 432$ & $93 ; 54.4 ; 73.7$ & $87.7 ; 87.6 ; 45.2$ & - \\
\hline \multicolumn{5}{|l|}{ Aranda-Gallardo et al (2013) [36] } \\
\hline Hendrich Fall Risk Model & - & 62.8 & 64.0 & - \\
\hline Morse Fall Scale & - & 75.5 & 67.7 & - \\
\hline STRATIFY & - & 80.0 & 67.5 & - \\
\hline \multicolumn{5}{|l|}{ Matarese et al (2014) [40] } \\
\hline Hendrich II Fall Risk Model & - & 92 & 37 & - \\
\hline STRATIFY & - & 63 & 71 & - \\
\hline \multicolumn{5}{|l|}{ Lusardi et al (2017) [25] } \\
\hline Berg Balance Scale & 1130 & 41 & 88 & - \\
\hline Five Times Sit-To-Stand test & 3319 & 59 & 63 & - \\
\hline Timed Up and Go (cut off $>0.74 \mathrm{~s} / \geq 12 \mathrm{~s}$ ) & 6410 & $56 ; 31$ & $65 ; 85$ & - \\
\hline Performance-Oriented Mobility Assessment (Tinetti) & 1374 & 53 & 69 & - \\
\hline Single-Limb stance (cut off $>6.5 />12.7$ ) & 3015 & $19 ; 90$ & $63 ; 49$ & - \\
\hline \multicolumn{5}{|l|}{ Park and Lee (2017) [41] } \\
\hline Berg Balance Scale & 1690 & 72 & 73 & $0.84(0.02)$ \\
\hline \multicolumn{5}{|l|}{ Nunan et al (2018) [37] } \\
\hline Downton Fall Risk Index & - & 91 & 39 & - \\
\hline Five Times Sit-To-Stand test & - & 86 & 91 & - \\
\hline Timed Up and Go & - & 49 & 72 & - \\
\hline Performance-Oriented Mobility Assessment (Tinetti) & - & $64 ; 85$ & $66 ; 56$ & - \\
\hline STRATIFY & - & 50 & 76 & - \\
\hline \multicolumn{5}{|l|}{ Park (2018) [38] } \\
\hline Berg Balance Scale & 570 & 73 & 90 & $0.97(0.02)$ \\
\hline Downton Fall Risk Index & 231 & 84 & 26 & - \\
\hline Hendrich II Fall Risk Model & 1754 & 76 & 60 & $0.75(0.05)$ \\
\hline Mobility Interaction chart & 286 & 53 & 73 & - \\
\hline STRATIFY & 2245 & 89 & 67 & $0.81(0.30)$ \\
\hline Timed Up and Go & 427 & 76 & 49 & $0.80(0.04)$ \\
\hline Tinetti Balance scale & 284 & 68 & 56 & - \\
\hline
\end{tabular}


${ }^{\mathrm{a}}$ Not applicable.

bSTRATIFY: St Thomas's Risk Assessment Tool in Falling Elderly.

Table 3. Range of sensitivity and specificity of identified fall risk assessment measures compared with the Aachen Falls Prevention Scale.

\begin{tabular}{|c|c|c|c|}
\hline Type of fall risk assessment measure and name & $\begin{array}{l}\text { Mean sensitivity, } \% \\
\text { (range) }\end{array}$ & $\begin{array}{l}\text { Mean specificity, \% } \\
\text { (range) }\end{array}$ & $\begin{array}{l}\text { Area under the } \\
\text { curve, mean (range) }\end{array}$ \\
\hline \multicolumn{4}{|l|}{ Functional } \\
\hline Berg Balance Scale & $65.8(41-77)$ & $84.3(73-90)$ & $0.90(0.84-0.97)$ \\
\hline Timed Up and Go & $59.8(31-87)$ & $71.6(49-87)$ & 0.80 \\
\hline Performance-Oriented Mobility Assessment (Tinetti) & $70.5(53-85)$ & $66.3(56-74)$ & $-^{\mathrm{a}}$ \\
\hline Five Times Sit-To-Stand test & $72.5(59-86)$ & $77(63-91)$ & - \\
\hline \multicolumn{4}{|l|}{ Multifactorial } \\
\hline Downton Fall Risk Index & $88.5(84-91)$ & $30.6(26-39)$ & - \\
\hline Morse Score & $81.5(73.2-95.7)$ & $65.6(54.0-75.1)$ & - \\
\hline STRATIFY ${ }^{b}$ & $71.9(50-93)$ & $71.7(45.2-87.7)$ & 0.81 \\
\hline Hendrich II Fall Risk Model & $84(76-92)$ & $48.5(37-60)$ & 0.75 \\
\hline Aachen Falls Prevention Scale (primary outcome parameter) & 57.0 & 76.7 & $0.724(0.692-0.756)$ \\
\hline Aachen Falls Prevention Scale ( 1 out of the 3 outcome parameters) & 90.0 & 50.0 & $0.693(0.629-0.756)$ \\
\hline
\end{tabular}

${ }^{\mathrm{a}}$ Not applicable.

bSTRATIFY: St Thomas's Risk Assessment Tool in Falling Elderly.

\section{Discussion}

\section{Principal Findings}

\section{Sensitivity and Specificity of the Aachen Falls Prevention Scale}

In this paper, the sensitivity and specificity of the AFPS were determined using a meta-analysis based on 2 independent studies. The results showed that by using the primary outcome parameter of the AFPS to discriminate between fallers and nonfallers, a pooled sensitivity of $57.0 \%$ and a pooled specificity of $76.7 \%$ can be achieved. If discrimination between fallers and nonfallers is based on a positive subscale (risk of falling present), the pooled sensitivity can be increased to $90.0 \%$, whereas the pooled specificity thereby decreases to $50.0 \%$. The AFPS, thus, exhibits an adequate combination of the necessary abilities that a patient-driven self-assessment tool should have. If all 3 outcomes are used, the fall risk is overestimated rather than underestimated, as sensitivity is about $90.0 \%$. As a result, older adults may become more proactive and conduct a professional fall risk assessment at a clinic, even though it might just be a false alarm. Furthermore, the 2 studies investigated by Knobe et al [31] and by Rasche et al [32] showed that the AFPS can be used by users independently via a paper manual as part of a postal survey or via a digital manual as part of a Web-based survey. This indicates that, in addition to the specific test accuracy parameters, this instrument also fulfills the requirement of patient-driven fall risk assessment as stated in the Introduction. To what extent, however, this instrument has a positive effect on the work of family doctors within the guidelines of fall risk assessment of older adults remains unclear.

\section{Comparison of the Aachen Falls Prevention Scale With Established Fall Risk Assessment Measures}

The systematic literature research conducted in the second step identified 9 different fall risk assessment measures, which were examined in at least two independent reviews. Identified reviews revealed a variety of reported sensitivity and specificity values. Within the group of functional fall risk assessment measures, Timed Up and Go [25,37-39], Berg Balance Scale [25,38,39,41], and Performance-Oriented Mobility Assessment (POMA) $[25,37,39]$ were most frequently discussed and analyzed within identified literature. The multifactorial fall risk assessment measures St Thomas's Risk Assessment Tool in Falling Elderly (STRATIFY) [26,36-38,40] and Downton Fall Risk Index $[26,37,38]$ were most frequently investigated within identified reviews.

The lowest sensitivity in a single study, as well as on average, was identified for the Timed Up and Go test, followed by the mountain balance scale. It is noteworthy that the functional assessments show a lower sensitivity in comparison with the characteristic values of the multifactorial assessments. Functional assessments, on the other hand, have on average a higher specificity than multifactorial assessments. Compared with these instruments, the AFPS has the advantage that a high specificity of $76.6 \%$ or a high sensitivity of $90.0 \%$ can be achieved by selecting the considered outcome parameter (primary or 1 of the 3 subscales).

The AFPS, thus, offers an approach for mapping the advantages of both a highly sensitive and a highly specific test. Although the databases need to be strengthened by further studies, results show a promising approach. Compared with all the risk assessment measures examined in this review, the AFPS shows 
similar performance based on calculated sensitivity, specificity, and AUC. In addition, the AFPS has the advantage that it can be used by patients or caregivers themselves to monitor the risk of individual falls in the long term.

\section{Limitations}

The limitations of this study and the studies presented here are two-fold. On the one hand, limitations are to be discussed with regard to the investigation of the test accuracy of the AFPS, and on the other hand, limitations are to be discussed with regard to the systematic literature research conducted.

The study to examine the test accuracy is limited by the study size, which is small compared with the examination of established fall risk assessment measures. A total number of 259 persons were examined. The data were collected in a controlled telephone study and in an anonymous Web-based survey in the second study. For a more comprehensive investigation of the test accuracy, a stronger focus on controlled patient groups from the clinical context should be included in further studies to achieve a more detailed patient segmentation with regard to the risk of falls. Furthermore, the inclusion of only 2 studies did not allow for an in-depth analysis using the MetaDiSc1.4 software. The inclusion of further studies is necessary for the analysis using ROCs by MetaDiSc1.4. Thus, corresponding curves were analyzed using SPSS.

Regarding the literature review and comparison, further limitations need to be considered in the interpretation of the stated results. Correct data aggregation based on different identified reviews was challenging as different cut-off points were chosen but not reported comprehensibly. Furthermore, sensitivity and specificity values of established fall risk assessment measures are not drawn from results of primary studies but from reviews that have synthesized the results already. In this respect, the validity of the comparison must be limited. Furthermore, the parameters for the sensitivity and specificity of the individual fall risk assessment measures extracted from the reviews are based on a different number of studies and contain study populations of different sizes. Thus, the limitations of the identified reviews with regard to the significance of the parameters specified there are also relevant for this contribution. Given these limitations, the results should be interpreted with some caution, and further studies designed to investigate test accuracy by direct comparison with the same study population should be conducted.

\section{Conclusions}

This study investigated the test accuracy of the AFPS as a patient-driven self-assessment tool compared with established tools such as Timed Up and Go, POMA, STRATIFY, or
Downton Fall Risk Index. This study showed that the AFPS is a promising tool for patient-driven fall risk assessment. It is quick and easy to use.

The AFPS showed suitable pooled sensitivity $(57.0 \%$; $95 \%$ CI $0.467-0.669)$ as well as a suitable specificity $(76.7 \%$; $95 \%$ CI $0.694-0.831)$ regarding discrimination between fallers and nonfallers by primary outcome. Sensitivity of the AFPS could be increased up to $90.0 \%$ (95\% CI $0.824-0.951)$ and a specificity of $50.0 \%$ (95\% CI $0.420-0.580$ ) if 1 out of the 3 parameters of the AFPS is used to discriminate between fallers and nonfallers.

Thereby, the AFPS shows an adequate combination of the necessary abilities that a patient-driven self-assessment tool should have. If it is used as prescribed (all 3 subscales are used), the fall risk is rather overestimated than underestimated. Thereby, older adults might get sensitized and consult a physician for clinical fall risk assessment even in the case of a false alarm.

The systematic analysis of existing reviews of fall risk measures shows the multitude of available measures and the range of associated sensitivity and specificity values. No outstanding measure was identified in this study, which illustrates the difficulty of selecting these measures in a clinical context. Nevertheless, we were also able to show that the newly developed AFPS is a suitable instrument with which fall patients and elderly people can independently assess and monitor their individual fall risk in the long term. In particular, the approach of bringing this method to the smartphone of affected or interested older adults using an app constitutes a promising approach, as its sensitivity and specificity are comparable with established fall risk assessment measures.

Nevertheless, the multitude of methods reviewed in this study was developed with a focus on clinical use, as the methods are intended to support the assessment of the risk of falls by physicians or medical specialists. Instruments that are supposed to start one step sooner in the process and enable the patient to assess the individual risk of falling independently are not yet widespread. One instrument that can be used in this context is the AFPS. Other studies have already shown that this instrument, in form of a health app, can be and is used by older adults to assess their individual risk of falling [24].

All in all, according to the investigated data, the AFPS and thus the AFPA are suitable approaches for increasing patient autonomy and simplifying the process of individual fall risk assessment. Through the application of AFPS and the further spread of AFPA, older people can be made aware of the risk of falling and clinical resources can be saved through the initial self-assessment by the older adults themselves.

\section{Acknowledgments}

This publication is part of the research project TECH4AGE, financed by the Federal Ministry of Education and Research (BMBF, under grant \#16SV7111) and promoted by VDI/VDE Innovation + Technik GmbH.

\section{Conflicts of Interest}

None declared. 


\section{References}

1. Jansson B. Research on the prevention of fall injuries still makes prediction for practice difficult. Age Ageing 2007 May;36(3):351-352. [doi: 10.1093/ageing/afm027] [Medline: 17379604]

2. Gillespie LD, Robertson MC, Gillespie WJ, Sherrington C, Gates S, Clemson LM, et al. Interventions for preventing falls in older people living in the community. Cochrane Database Syst Rev 2012 Sep 12(9):CD007146. [doi: 10.1002/14651858.CD007146.pub3] [Medline: 22972103]

3. Swift CG. Care of older people: falls in late life and their consequences-implementing effective services. Br Med J 2001 Apr 7;322(7290):855-857 [FREE Full text] [Medline: 11290646]

4. Liu SW, Obermeyer Z, Chang Y, Shankar KN. Frequency of ED revisits and death among older adults after a fall. Am J Emerg Med 2015 Aug;33(8):1012-1018 [FREE Full text] [doi: 10.1016/j.ajem.2015.04.023] [Medline: 25983268]

5. Klos K, Simons P, Mückley T, Karich B, Randt T, Knobe M. [Fractures of the ankle joint in elderly patients]. Unfallchirurg 2017 Nov;120(11):979-992. [doi: 10.1007/s00113-017-0423-1] [Medline: 29052752]

6. Gulich M. A new DEGAM guideline "Elderly Falling Patients". Z Allg Med 2004;80(10):416-420. [doi: 10.1055/s-2004-820396]

7. National Institute for Health and Care Excellence. 2013 Jun. Falls in older people: assessing risk and prevention: (CG161) URL: https://www.nice.org.uk/guidance/cg161 [accessed 2019-02-11] [WebCite Cache ID 766U2ODdr]

8. US Preventive Services Task Force. 2018 Apr. Final Recommendation Statement: Falls Prevention in Community-Dwelling Older Adults: Interventions 2018 URL: https://www.uspreventiveservicestaskforce.org/Page/Document/ RecommendationStatementFinal/falls-prevention-in-older-adults-interventions1 [accessed 2018-10-24] [WebCite Cache ID 73P6icE3S]

9. Irvine L, Conroy SP, Sach T, Gladman JR, Harwood RH, Kendrick D, et al. Cost-effectiveness of a day hospital falls prevention programme for screened community-dwelling older people at high risk of falls. Age Ageing 2010 Nov;39(6):710-716 [FREE Full text] [doi: 10.1093/ageing/afq108] [Medline: 20833862]

10. Spice CL, Morotti W, George S, Dent TH, Rose J, Harris S, et al. The Winchester falls project: a randomised controlled trial of secondary prevention of falls in older people. Age Ageing 2009 Jan;38(1):33-40. [doi: 10.1093/ageing/afn192] [Medline: 18829689]

11. Pape H, Schemmann U, Foerster J, Knobe M. The 'Aachen Falls Prevention Scale' - development of a tool for self-assessment of elderly patients at risk for ground level falls. Patient Saf Surg 2015;9:7 [FREE Full text] [doi: 10.1186/s13037-014-0055-0] [Medline: 25685196]

12. Panzer VP, Wakefield DB, Hall CB, Wolfson LI. Mobility assessment: sensitivity and specificity of measurement sets in older adults. Arch Phys Med Rehabil 2011 Jun;92(6):905-912 [FREE Full text] [doi: 10.1016/j.apmr.2011.01.004] [Medline: 21621667]

13. Ferrucci L, Guralnik JM, Studenski S, Fried LP, Cutler GB, Walston JD, Interventions on Frailty Working Group. Designing randomized, controlled trials aimed at preventing or delaying functional decline and disability in frail, older persons: a consensus report. J Am Geriatr Soc 2004 Apr;52(4):625-634. [doi: 10.1111/j.1532-5415.2004.52174.x] [Medline: 15066083]

14. Vassallo M, Poynter L, Sharma JC, Kwan J, Allen SC. Fall risk-assessment tools compared with clinical judgment: an evaluation in a rehabilitation ward. Age Ageing 2008 May;37(3):277-281. [doi: 10.1093/ageing/afn062] [Medline: 18456792]

15. Knobe M, Giesen M, Plate S, Gradl-Dietsch G, Buecking B, Eschbach D, et al. The Aachen Mobility and Balance Index to measure physiological falls risk: a comparison with the Tinetti POMA Scale. Eur J Trauma Emerg Surg 2016 Oct;42(5):537-545. [doi: 10.1007/s00068-016-0693-2] [Medline: 27287271]

16. Gates S, Smith LA, Fisher JD, Lamb SE. Systematic review of accuracy of screening instruments for predicting fall risk among independently living older adults. J Rehabil Res Dev 2008;45(8):1105-1116 [FREE Full text] [doi: 10.1682/JRRD.2008.04.0057] [Medline: 19235113]

17. Tinetti M. Performance-oriented assessment of mobility problems in elderly patients. J Am Geriatr Soc 1986 Feb;34(2):119-126. [doi: 10.1111/j.1532-5415.1986.tb05480.x] [Medline: 3944402]

18. Tinetti ME, Kumar C. The patient who falls: 'It's always a trade-off'. J Am Med Assoc 2010 Jan 20;303(3):258-266 [FREE Full text] [doi: 10.1001/jama.2009.2024] [Medline: 20085954]

19. Bauer C, Gröger I, Rupprecht R, Marcar V, Gaßmann K. Prediction of future falls in a community dwelling older adult population using instrumented balance and gait analysis. Z Gerontol Geriat 2015 Apr 11;49(3):232-236. [doi: 10.1007/s00391-015-0885-0] [Medline: 25862429]

20. Hauer K, Lamb SE, Jorstad EC, Todd C, Becker C, PROFANE-Group. Systematic review of definitions and methods of measuring falls in randomised controlled fall prevention trials. Age Ageing 2006 Jan;35(1):5-10. [doi: 10.1093/ageing/afi218] [Medline: 16364930]

21. Ungar A, Rafanelli M, Iacomelli I, Brunetti MA, Ceccofiglio A, Tesi F, et al. Fall prevention in the elderly. Clin Cases Miner Bone Metab 2013 May;10(2):91-95 [FREE Full text] [Medline: 24133524]

22. Woo J, Hong A, Lau E, Lynn H. A randomised controlled trial of Tai Chi and resistance exercise on bone health, muscle strength and balance in community-living elderly people. Age Ageing 2007 May;36(3):262-268. [doi: 10.1093/ageing/afm005] [Medline: 17356003] 
23. Campbell AJ, Robertson MC. Rethinking individual and community fall prevention strategies: a meta-regression comparing single and multifactorial interventions. Age Ageing 2007 Nov;36(6):656-662. [doi: 10.1093/ageing/afm122] [Medline: $\underline{18056731]}$

24. Rasche P, Mertens A, Bröhl C, Theis S, Seinsch T, Wille M, et al. The 'Aachen fall prevention App' - a smartphone application app for the self-assessment of elderly patients at risk for ground level falls. Patient Saf Surg 2017;11:14 [FREE Full text] [doi: 10.1186/s13037-017-0130-4] [Medline: 28503199]

25. Lusardi MM, Fritz S, Middleton A, Allison L, Wingood M, Phillips E, et al. Determining risk of falls in community dwelling older adults: a systematic review and meta-analysis using posttest probability. J Geriatr Phys Ther 2017;40(1):1-36 [FREE Full text] [doi: 10.1519/JPT.0000000000000099] [Medline: 27537070]

26. Oliver D, Daly F, Martin FC, McMurdo ME. Risk factors and risk assessment tools for falls in hospital in-patients: a systematic review. Age Ageing 2004 Mar;33(2):122-130. [doi: 10.1093/ageing/afh017] [Medline: 14960426]

27. Lalkhen AG, McCluskey A. Clinical tests: sensitivity and specificity. BJA Educ 2008 Nov 12;8(6):221-223. [doi: 10.1093/bjaceaccp/mkn041]

28. Zamora J, Abraira V, Muriel A, Khan K, Coomarasamy A. Meta-DiSc: a software for meta-analysis of test accuracy data. BMC Med Res Methodol 2006 Jul 12;6:31 [FREE Full text] [doi: 10.1186/1471-2288-6-31] [Medline: 16836745]

29. Greiner M, Pfeiffer D, Smith RD. Principles and practical application of the receiver-operating characteristic analysis for diagnostic tests. Prev Vet Med 2000 May 30;45(1-2):23-41. [doi: 10.1016/S0167-5877(00)00115-X] [Medline: 10802332]

30. Habibzadeh F, Habibzadeh P, Yadollahie M. On determining the most appropriate test cut-off value: the case of tests with continuous results. Biochem Med (Zagreb) 2016 Oct 15;26(3):297-307 [FREE Full text] [doi: 10.11613/BM.2016.034] [Medline: 27812299]

31. Knobe M, Rasche P, Rentemeister L, Bliemel C, Bücking B, Bollheimer LC, et al. Evaluation eines einfachen Testverfahrens in der ambulanten Sturzprävention. [Evaluation of a simple screening tool for ambulant fall prevention]. Unfallchirurg 2018 Feb 2. [doi: 10.1007/s00113-018-0462-2] [Medline: 29396590]

32. Rasche P, Mertens A, Brandl C, Liu S, Buecking B, Bliemel C, et al. Satisfying product features of a fall prevention smartphone app and potential users' willingness to pay: web-based survey among older adults. JMIR Mhealth Uhealth 2018 Mar 27;6(3):e75 [FREE Full text] [doi: 10.2196/mhealth.9467] [Medline: 29588268]

33. PRISMA Statement. 2018. URL: http://prisma-statement.org [accessed 2018-07-04] [WebCite Cache ID 70euQlMzL]

34. Kung J, Chiappelli F, Cajulis OO, Avezova R, Kossan G, Chew L, et al. From systematic reviews to clinical recommendations for evidence-based health care: validation of revised assessment of multiple systematic reviews (R-AMSTAR) for grading of clinical relevance. Open Dent J 2010 Jul 16;4:84-91 [FREE Full text] [doi: 10.2174/1874210601004020084] [Medline: 21088686]

35. Sorgente A, Pietrabissa G, Manzoni GM, Re F, Simpson S, Perona S, et al. Web-based interventions for weight loss or weight loss maintenance in overweight and obese people: a systematic review of systematic reviews. J Med Internet Res 2017 Jun 26;19(6):e229 [FREE Full text] [doi: 10.2196/jmir.6972] [Medline: 28652225]

36. Aranda-Gallardo M, Morales-Asencio JM, Canca-Sanchez JC, Barrero-Sojo S, Perez-Jimenez C, Morales-Fernandez A, et al. Instruments for assessing the risk of falls in acute hospitalized patients: a systematic review and meta-analysis. BMC Health Serv Res 2013 Apr 2;13:122 [FREE Full text] [doi: 10.1186/1472-6963-13-122] [Medline: 23547708]

37. Nunan S, Brown WC, Henwood T, Parker D. Fall risk assessment tools for use among older adults in long-term care settings: a systematic review of the literature. Australas J Ageing 2018 Mar;37(1):23-33. [doi: 10.1111/ajag.12476] [Medline: 29168303]

38. Park S. Tools for assessing fall risk in the elderly: a systematic review and meta-analysis. Aging Clin Exp Res 2018 Jan;30(1):1-16. [doi: 10.1007/s40520-017-0749-0] [Medline: 28374345]

39. Perell KL, Nelson A, Goldman RL, Luther SL, Prieto-Lewis N, Rubenstein LZ. Fall risk assessment measures: an analytic review. J Gerontol A Biol Sci Med Sci 2001 Dec;56(12):M761-M766 [FREE Full text] [Medline: 11723150]

40. Matarese M, Ivziku D, Bartolozzi F, Piredda M, De Marinis MG. Systematic review of fall risk screening tools for older patients in acute hospitals. J Adv Nurs 2015 Jun;71(6):1198-1209. [doi: 10.1111/jan.12542] [Medline: 25287867]

41. Park S, Lee Y. The diagnostic accuracy of the Berg Balance Scale in predicting falls. West J Nurs Res 2017 Dec;39(11):1502-1525. [doi: 10.1177/0193945916670894] [Medline: 27784833]

\section{Abbreviations}

AFPA: Aachen Falls Prevention App

AFPS: Aachen Falls Prevention Scale

AUC: area under the curve

POMA: Performance-Oriented Mobility Assessment

PRISMA: Preferred Reporting Items for Systematic Reviews and Meta-Analysis

R-AMSTAR: Revised Assessment of Multiple SysTemAtic Reviews

ROC: receiver operating curve

STRATIFY: St Thomas's Risk Assessment Tool in Falling Elderly 
NICE: National Institute for Health and Care Excellence

US PSTF: United States Preventive Service Task Force

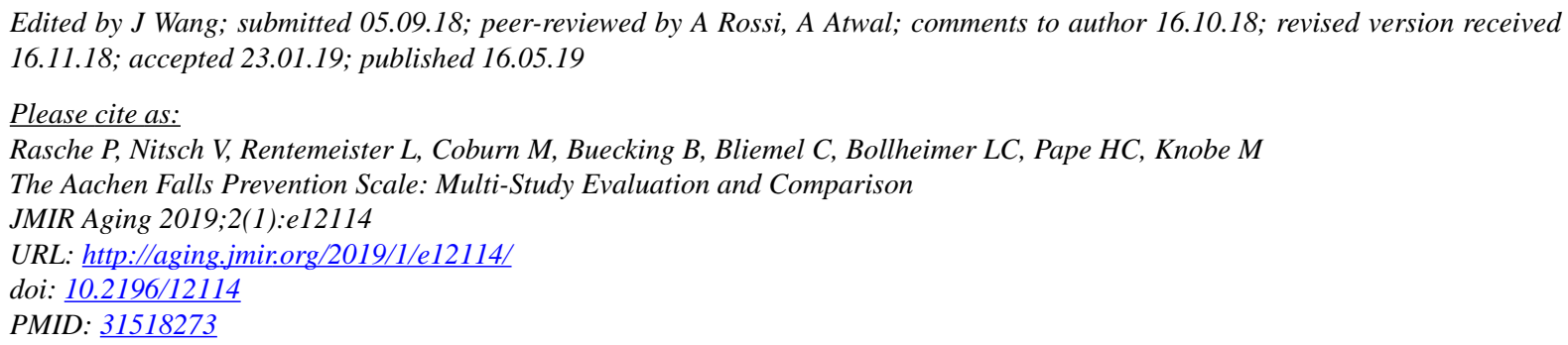

CPeter Rasche, Verena Nitsch, Lars Rentemeister, Mark Coburn, Benjamin Buecking, Christopher Bliemel, Leo Cornelius Bollheimer, Hans-Christoph Pape, Matthias Knobe. Originally published in JMIR Aging (http://aging.jmir.org), 16.05.2019. This is an open-access article distributed under the terms of the Creative Commons Attribution License (https://creativecommons.org/licenses/by/4.0/), which permits unrestricted use, distribution, and reproduction in any medium, provided the original work, first published in JMIR Aging, is properly cited. The complete bibliographic information, a link to the original publication on http://aging.jmir.org, as well as this copyright and license information must be included. 